\title{
Studi Penentuan Nilai Koefisien Pengaliran DAS Batang Arau di Kota Padang
}

\section{Study of Determination of Flow Coeffisient Value of Batang Arau Watershed in Padang City}

\author{
Fitri Handayani, Rahmania Hardiyenti, Indra Agus, Sadtim \& Hartati \\ Jurusan Teknik Sipil Politeknik Negeri Padang Kampus Limau Manis Padang \\ Telp. 0751-72590 Fax. 0751-72576 \\ Email: Fitrih610@gmail.com ; rhardiyenti224@gmail.com
}

\begin{abstract}
Batang Arau river is located $0^{\circ} 48^{\prime}$ up to $0^{\circ} 56^{\prime}$ SL (South Latitude) and on $100^{\circ} 21$ " up to $100^{\circ} 33^{\prime \prime} L E$ (Longitutede East), and upstream part water catcment area it is cover $30,90 \mathrm{~km}^{2}$ area. The above said catchment area is a region consist of densely .populated and also dominated by vegetation of natural forest, protected forest, people's forest, mixed forest, farm, recefield and yard. Based on site observation, most of the forest has changed become residant farms and settlement. This condition can be shown by land use map and change of runoff which was change from year to year. With this land use change however will also affecty changing of runoff coefficient. The goals of this study is to get flow coefficient (c) based on land use coefficient, debit AWLR, and based on SWAT application. Calculation of the coefficient based on land use map until be done by Arcgis method, debit AWLR using Hasper method and SWAT application. Study shown in period between 2009 - 2017, coefficient flow result is in range 0,36-0,37. Flow coefficient using AWLR result is in range 0,36-0,37, while flow coefficient using SWAT method is 0,25-0,36
\end{abstract}

Keywords : Flow Coefficient, Land Use, Method Hasper, AWLR, SWAT

\section{PENDAHULUAN}

Penggunaan lahan adalah suatu aktivitas manusia pada lahan yang langsung berhubungan dengan lokasi dan kondisi lahan (Sugiono, 2002). Perubahan tata guna lahan yang disebabkan oleh pertumbuhan penduduk dan sektor pembangunan yang meningkat dalam suatu kawasan DAS terutama di daerah hulu mempunyai dampak yang signifikan terhadap nilai limpasan permukaan, sehingga secara langsung mengakibatkan peningkatan pada nilai koefisien pengaliran (C) dan intensitas hujan yang tinggi menjadikan debit limpasan permukaan dari air hujan semakin besar, sehingga mengakibatkan banjir.

Perubahan tataguna lahan berdampak sangat besar terhadap aliran permukaan dan bawah permukaan yang pada akhirnya mempengaruhi ketersediaan sumber daya air dalam jangka panjang.
Perbandingan antara besarnya laju permukaan terhadap intensitas hujan disebut dengan koefisien pengaliran (C). Angka koefisien aliran permukaan ini merupakan salah satu indikator untuk menentukan kondisi fisik suatu DAS. Pada DAS yang baik, harga $C$ mendekati nol dan semakin rusak suatu DAS maka nilai C mendekati 1. ( Suripin, 2004). Faktor utama yang mempengaruhi nilai $\mathrm{C}$ ialah laju infiltrasi tanah, kemiringan lahan, penutup lahan, dan intensitas hujan. Adapun faktor lain yang dapat mempengaruhi nilai $\mathrm{C}$ ialah air tanah, derajat kepadatan tanah, porositas tanah, dan simpanan depresi.

Tujuan dari penelitian ini adalah untuk menentukan nilai koefisien pengaliran DAS Batang Arau berdasarkan klasifikasi tataguna lahan, debit $A W L R$ dan SWAT

\section{METODOLOGI}

Lokasi penelitian berada di DAS Batang Arau, Sumatera Barat dengan titik 
koordinat $0^{\circ} 48^{\text {ee }}$ sampai dengan $0^{\circ} 56^{\text {ee }} \mathrm{LS}$ dan $100^{\circ} 21^{\prime \prime}$ sampai dengan $100^{\circ} 33^{\text {ee }} \mathrm{BT}$, dengan ketinggian 0 sampai dengan 1.210 $\mathrm{m}$ dari permukaan laut $(\mathrm{mdpl})$ dengan outlet penelitian berada di Sungai Batang Arau. Penempatan outlet ini bertujuan karena debit sungai yang dianalisis diharuskan berada pada lokasi aliran yang akan keluar dari DAS tersebut. Sungai Batang Arau merupakan sungai utama pada DAS Batang Arau, yang sumber airnya berasal dari Sungai Lubuk Paraku, Sungai Padang Idas, dan Sungai Lubuk Sarik. Daerah tangkapan air DAS Batang Arau bagian hulu hanya sekitar 3.090 hektar $(30,90 \mathrm{~km} 2)$, meliputi kawasan konservas, hutan lindung, dan lahan milik masyarakat.

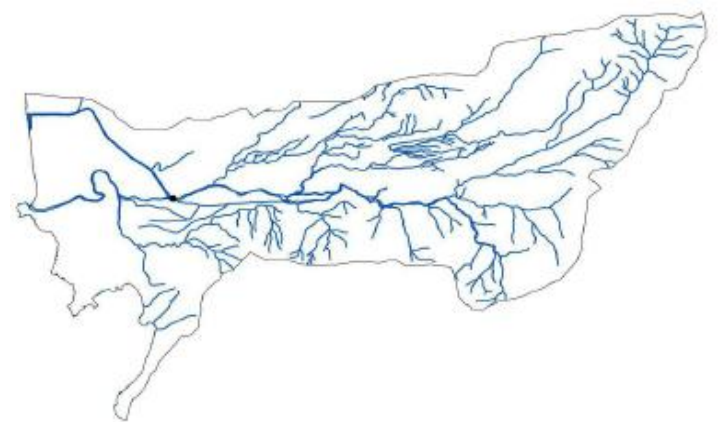

Gambar 1. DAS Batang Arau

Penelitian mengenai dampak perubahan nilai koefisien pengaliran DAS Batang Arau ini dilakukan melalui 2 (dua) tahap utama, yaitu tahap pengumpulan data dan analisa data. Pada tahap pengumpulan data, data yang dikumpulkan meliputi data peta penggunaan lahan tahun 2009, 2011, 2014, 2015 dan 2017 yang diperoleh dari Dinas PUPR Kota Padang, data debit AWLR DAS Batang Arau dan Klimatologi yang diperoleh dari Dinas PSDA Kota Padang, data $D E M$ wilayah DAS Batang Arau dari ASTER Global DEM, peta dan data tanah dari data global, dan data Intensitas hujan dari tahun 2008 - 2018 yang diperoleh dari Stasiun Satelit NASA.Tahap selanjutnya yaitu analisa data. Analisa data meliputi penganalisaan perubahan nilai koefisien pengaliran dari tahun 2009 - 2017 dengan menggunakan tiga metode perhitungan, yakni: berdasarkan peta tataguna lahan, berdasarkan debit AWLR, dan dengan menggunakan aplikasi SWAT (Soil and Water Assessment Tool).

a. Untuk analisa peta tataguna lahan dengan menggunakan tabel koefisien runoff untuk menentukan nilai koefisien sesuai keterangan yang telah ditentukan pada peta tersebut. Nilai koefisien runoff yang digunakan ialah berdasarkan tabel 1 hubungan antara koefisien runoff dan daerah aliran, standar koefisien runoff terhadap kondisi permukaan (tabel 2) dan koefisien run off rata-rata terhadap tataguna lahan (tabel 3)

Tabel 1. Hubungan antara koefisien runoff dan daerah aliran.

\begin{tabular}{ll}
\hline Keadaan Daerah Aliran & Koefisien Runoff \\
\hline Bergunung dan curam & $0,75-0,90$ \\
Pegunungan tersier & $0,70-0,80$ \\
Sungai berhutan dibagian atas dan bawahnya & $0,50-0,75$ \\
Tanah datar yang ditanami & $0,45-0,60$ \\
Sawah waktu diairi & $0,70-0,80$ \\
Sungai bergunung & $0,75-0,85$ \\
Sungai daratan & $0,45-0,75$
\end{tabular}

Sumber : Dr Mononobe dalam Suyono S (1999) 
Tabel 2. Standar Koefisien Runoff terhadap kondisi permukaan

\begin{tabular}{llr}
\hline Kondisi Permukiman (Groudn Surface) & Koefisien Runoff \\
\hline Roadway & -Paved road & $0,74-0,95$ \\
& - Gravel road & $0,30-0,70$ \\
Shoulder and Slope & - Fine Grainde Soil & $0,40-0,65$ \\
& - Coarse Grainde Soil & $0,10-0,30$ \\
& - Hard Rock & $0,70-0,85$ \\
& - Soft Rock & $0,50-0,75$ \\
Turf and Slope & & \\
& - Grade 0 -2\% & $0,05-0,10$ \\
& - Grade 2 -7\% & $0,10-0,15$ \\
Turf Covered Cohesive Soil & - Grade > 7\% & $0,15-0,20$ \\
& - Grade 0 -2\% & \\
& - Grade 2 -7\% & $0,50-0,10$ \\
Roof & - Grade $>7 \%$ & $0,10-0,15$ \\
Bare Lot & & $0,25-0,35$ \\
Park with Abondant and trees & & $0,75-0,95$ \\
Flat Mountains Area & & $0,21-0,40$ \\
Steep Mountains Area & & $0,10-0,25$ \\
Pady Field and water Body & & $0,30-0,70$ \\
Cultivated Field & $0,50-0,70$ \\
\hline
\end{tabular}

Tabel 3. Koefisien Runoff rata-rata terhadap tataguna lahan

\begin{tabular}{lll}
\hline Tataguna Lahan (Land Use) & & Koefisien Runoff \\
\hline Commersial Area & : - Downtown Area & $0,75-0,95$ \\
& - Area Adjacentto Downtown & $0,50-0,70$ \\
& & \\
Industrial Area & - Less Congested Area & $0,50-0,80$ \\
& - Congested Area & $0,60-0,90$ \\
Residential Area & & \\
& - Residential Area with Little Bare Lot & $0,65-0,80$ \\
& - Rousing Estate & $0,50-0,70$ \\
Green Zone \& Others & - Residential Area with Little Bare Lots & $0,30-0,70$ \\
& And Gardens & $0,10-0,25$ \\
& - Park and Graveyard & $0,20-0,35$ \\
& - Athletic Ground & $0,20-0,40$ \\
& - Marshalling Yard & $0,10-0,30$ \\
\hline
\end{tabular}


b. Untuk data debit AWLR didapat dari Dinas PSDA Kota Padang dan daerah yang ditinjau yaitu dari bendung Ujung Tanah sampai ke daerah hulu DAS Batang Arau.Pada penelitian ini, untuk menentukan nilai koefisien pengaliran berdasarkan debit AWLR dihitung dengan menggunakan metode Hasper.

Metode Hasper yang digunakan untuk menghitung debit maksimum dirumuskan sebagai berikut:

Qmaks $=\alpha x \beta x I x A$

Keterangan rumus:

Qmaks $=$ debit maksimum $\left(\mathrm{m}^{3} / \mathrm{dt}\right)$

$\alpha=$ koefisien pengaliran

$\beta=$ koefisien reduksi

$\mathrm{I}=$ intensitas hujan $\left(\mathrm{m}^{3} / \mathrm{dt} / \mathrm{Km}^{2}\right)$

$\mathrm{A}=$ luas daerah pengaliran $\left(\mathrm{Km}^{2}\right)$

Koefisien pengaliran $(\alpha)$ ditentukan dengan rumus:

$$
\alpha=\frac{1+0,012 \times \mathrm{A}^{0,7}}{1+0,075 \times \mathrm{A}^{0,7}} \times \mathrm{I}
$$

Koefisien reduksi $(\beta)$ ditentukan dengan rumus :

$$
\frac{1}{\beta}=1+\frac{1+3,7 \times 10^{0,4 \times t}}{t^{2}+15} \times \frac{A^{3 / 4}}{12}
$$

Waktu konsentrasi $\left(t_{c}\right)$ ditentukan dengan rumus :

$$
\mathrm{tc}=0,1 \times \mathrm{xL}^{0,8} \mathrm{xS}^{-0,3}
$$

Keterangan rumus:

$$
\begin{aligned}
& \mathrm{L}=\text { panjang sungai }(\mathrm{Km}) \\
& \mathrm{S}=\text { kemiringan dasar sungai rata-rata }
\end{aligned}
$$

Besarnya curah hujan ( $\mathrm{r}$ dalam satuan $\mathrm{mm}$ ) untuk lama hujan tertentu $(\mathrm{t}=\mathrm{tc}$ dalam satuan jam) dan (hujan harian maksimum R24 dalam satuan $\mathrm{mm}$ ) dengan rumus sebagai berikut :

Untuk $<2$ jam :

$$
r=\frac{t \times R_{24}}{t+1-0,0008 \times\left(260-R^{24}\right)(2-t)}
$$

Untuk 2 jam $<\mathrm{t}<19$ jam :

$$
r=\frac{t \times R_{24}}{t+1}
$$

Untuk 19 jam $<\mathrm{t}<30$ hari :

$\mathrm{R}=0,707 \times \mathrm{R}_{24} \times(\mathrm{t}+1)^{1 / 2}$.

Besarnya intensitas hujan (I dalam satuan $\mathrm{m}^{3} / \mathrm{dt} / \mathrm{km}^{2}$ ) ditentukan berdasarkan hubungan antara $\mathrm{r}(\mathrm{mm})$ dan $\mathrm{t}$ (jam) dengan rumus :

$$
\mathrm{I}=\frac{\mathrm{r}}{3,6 \mathrm{xt}}
$$

c. Analisa data berdasarkan permodelan SWAT meliputi analisis perubahan penutup lahan dan HRU, analisis debit aliran masing-masing HRU dan analisis akurasi. Data yang diperlukan ialah data DEM dari ASTER Global DEM, data karakteristik tanah DAS Batang Arau, klimatologi yang didapat dari Dinas PSDA Kota Padang dari tahun $2008-2018$.

\section{HASIL DAN PEMBAHASAN}

Koefisien pengaliran ( $\mathrm{C}$ ) yaitu bilangan yang menunjukkan perbandingan antara besarnya aliran permukaan dan besarnya curah hujan. Angka koefisien aliran permukaan ini merupakan salah satu indikator untuk menentukan kondisi fisik suatu DAS. Nilai $\mathrm{C}$ berkisar antara 0 sampai 1 . Nilai $\mathrm{C}=0$ menunjukan bahwa semua air terintersepsi dan terinfiltrasi ke dalam tanah, sebaliknya untuk nilai $\mathrm{C}=1$ menunjukkan bahwa semua air hujan mengalir sebagai aliran permukaan. Pada DAS yang baik, harga $C$ mendekati nol dan semakin rusak suatu DAS maka nilai C mendekati 1. ( Suripin, 2004 )

Koefisien pengaliran ( C ) dihitung karena sangat mempengaruh perubahan debit banjir yang terjadi pada suatu DAS. Faktor utama yang dapat mempengaruhi nilai $\mathrm{C}$ ini ialah laju infiltrasi tanah, kemiringan lahan, penutup lahan, dan intensitas hujan.

Adapun faktor lain yang dapat mempengaruhi nilai $\mathrm{C}$ ialah air tanah, derajat kepadatan tanah, porositas tanah, dan simpanan depresi. 
a) Berdasarkan peta penggunaan lahan

Dari peta penggunaan lahan yang digunakan, didapatkan hasil luasan daerah berdasarkan penggunaan lahan. Selanjutnya menentukan nilai koefisien pengaliran ( C ) berdasarkan tabel sesuai dengan penggunaan lahan. Nilai koefisien yang didapat setiap penggunaan lahan dibagi dengan luas area keseluruhan sehingga mendapatkan nilai koefisien pengaliran rata-rata pada DAS tersebut.

Rekap klasifikasi keterangan penggunaan lahan lahan peta penggunaan lahan dari tahun 2009 sampai 2017, lihat tabel 4.

Tabel 4. Penggunaan Lahan pada DAS Batang Arau

\begin{tabular}{llrrrrr}
\hline No & Keterangan & \multicolumn{5}{c}{ Luas Area $(\mathrm{km} 2)$} \\
& & 2009 & \multicolumn{1}{c}{2011} & 2014 & \multicolumn{1}{c}{2015} & \multicolumn{1}{c}{2017} \\
\hline 1 & Hutan & 53.34 & 54.45 & 73.12 & 81.51 & 92.35 \\
2 & Pemukiman & 34.59 & 34.59 & 36.42 & 39.52 & 35.64 \\
3 & Pertambangan & 3.73 & 3.73 & 3.71 & 3.58 & 5.99 \\
4 & Pertanian & 75.77 & 74.66 & 40.85 & 28.03 & 16.09 \\
5 & Sawah & 3.78 & 3.73 & 17.11 & 17.48 & 20.73 \\
6 & Sungai & 0.91 & 0.91 & 0.91 & 2.02 & 1.33 \\
\hline
\end{tabular}

Dari data penggunaan lahan DAS Batang Arau tersebut, bisa dihitung nilai koefisien pengaliran berdasarkan penggunaan lahan dengan menggunakan nilai koefisien dari tabel 1-3 yang telah dijelaskan sebelumnya. Berikut adalah hasil rekap dari perhitungan nilai koefisien pengaliran berdasarkan penggunaan lahan yang dapat dilihat pada tabel 5.

Tabel 5. Rekap Hasil Koefisien

Penggunaan Lahan

\begin{tabular}{llc}
\hline No & Tahun & $\begin{array}{c}\text { Nilai Koefisien } \\
\text { Pengaliran }\end{array}$ \\
\hline 1 & 2009 & 0,365 \\
2 & 2011 & 0,364 \\
3 & 2014 & 0,373 \\
4 & 2015 & 0,371 \\
5 & 2017 & 0,375 \\
\hline
\end{tabular}

Tabel 6. Rekap Hasil Koefisien Pengaliran (C) berdasarkan perhitungan debit AWLR

\begin{tabular}{llc}
\hline No & Tahun & $\begin{array}{c}\text { Nilai Koefisien } \\
\text { Pengaliran }\end{array}$ \\
\hline 1 & 2009 & 0,12 \\
2 & 2011 & 0,22 \\
3 & 2014 & 0,37 \\
4 & 2015 & 0,59 \\
5 & 2017 & 0,83 \\
\hline
\end{tabular}

b) Berdasarkan debit AWLR

Perhitungan nilai koefisien pengaliran berdasarkan debit AWLR dengan menggunakan metode Hasper. Metode ini dipilih dikarenakan luas DAS Batang Arau dari titik yang ditinjau yaitu dari Bendung Ujung Tanah sampai ke daerah hulu sungai DAS Batang Arau seluas $117.94 \mathrm{Km}^{2}$, yang mana memenuhi syarat untuk pemakaian dengan metoda Hasper yaitu kurang dari atau sama dengan $300 \mathrm{Km}^{2}$. (Kamiana, 2012)

Berikut adalah hasil rekap nilai koefisien pengaliran berdasarkan data debit AWLR DAS Batang Arau

c) Berdasarkan pemodelan SWAT

Sebelum menentukan penggunaan lahan, terlebih dahulu dilakukan proses delineasi sungai. Delineasi sungai merupakan proses pembentukan atau penggambaran sungai pada suatu daerah aliran sungai (DAS) yang ditinjau. Delineasi sungai dilakukan dengan menggunakan ArcGIS dan dipadukan dengan SWAT untuk memperoleh unit respon hidrologi (HRU) seperti kemiringan, karakteristik tanah, dan kelas penggunaan lahan.

Setelah pemodelan SWAT dilakukan, maka bentuk pengeluaran dari pemodelan 
ini untuk nilai koefisien pengaliran seperti pada gambar berikut.

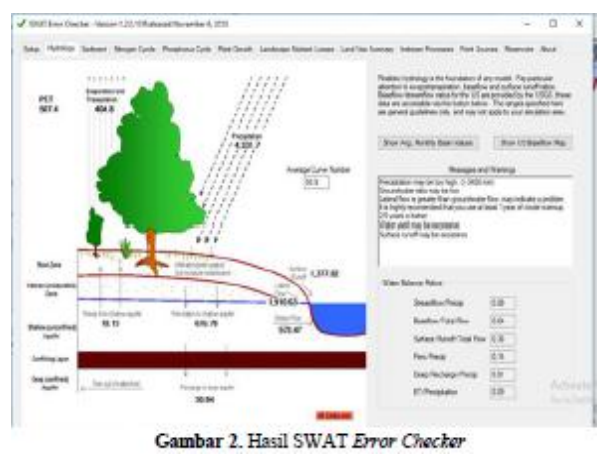

Hasil rekapan nilai koefisien pengaliran berdasarkan pemodelan SWAT ialah sebagai berikut.
Tabel 7. Rekap Hasil Koefisien Pengaliran

\begin{tabular}{|c|c|c|}
\hline \multicolumn{3}{|c|}{ ( C ) dengan Model SWAT } \\
\hline $\begin{array}{l}\mathrm{N} \\
\mathrm{T}\end{array}$ & & Nilai Koefisien Pengaliran \\
\hline 1 & 2009 & 0,25 \\
\hline 2 & 2011 & 0,22 \\
\hline 3 & 2014 & 0,24 \\
\hline 4 & 2015 & 0,35 \\
\hline 5 & 2017 & 0,36 \\
\hline
\end{tabular}

d).Perbandingan Nilai Koefisien Pengaliran ( C).

Berdasarkan hasil perhitungan analisa koefisien pengaliran ( $\mathrm{C}$ ) dengan menggunakan peta penggunaan lahan, debit AWLR, dan aplikasi SWAT didapat hasil perbandingan nilai koefisien pengaliran ( $\mathrm{C}$ ) seperti pada tabel 8 .

Tabel 8. Perbandingan Nilai Koefisien pengaliran

\begin{tabular}{|c|c|c|c|c|}
\hline Tahun & $\begin{array}{l}\text { Peta } \\
\text { lahan }\end{array}$ & Penggunaan & Debit AWLR & SWAT \\
\hline 2009 & 0,365 & & 0,12 & 0,25 \\
\hline 2011 & 0,364 & & 0,22 & 0,22 \\
\hline 2014 & 0,373 & & 0,37 & 0,24 \\
\hline 2015 & 0,371 & & 0,59 & 0,35 \\
\hline 2017 & 0,375 & & 0,83 & 0,36 \\
\hline
\end{tabular}

\section{SIMPULAN}

Berdasarkan hasil analisis dari peta tataguna lahan pada DAS Batang Arau selama tahun 2009 sampai dengan tahun 2017 , didapatkan nilai koefisien runoff berada pada rentang $0.36-0.37$. Hal ini dikarenakan pengaruh dari meningkatnya lahan yang beralih fungsi seiring dengan meningkatnya pembangunan di kawasan DAS. Jika ditinjau dari Debit AWLR DAS Batang Arau yang menggunakan metode Hasper, terjadi perubahan nilai koefisien runoff yang semakin besar dari tahun yang ditinjau dengan rentang nilai $\mathrm{C}$ nya ialah $0.12-0.83$. Pada perhitungan SWAT, diperoleh nilai koefisien pengaliran berada pada rentang $0.25-0.36$

\section{SARAN}

Saran untuk kantor PUPR Kota Padang bagian Tata Ruang sebaiknya dalam mengklasifikasi keterangan pada peta tataguna lahan sebaiknya pemberian keterangan penggunaan lahan setiap tahun seharusnya sama agar lebih mudah untuk di klasifikasikan atau mempersentasikan perubahan yang terjadi.

Penggunaan SWAT harus didukung dengan laptop atau komputer yang sesuai dengan kebutuhan operasi aplikasi SWAT tersebut. Hal tersebut karena pengoperasian SWAT sangat sensitif. 


\section{DAFTAR PUSTAKA}

[1] Arnold JG, Kiniry JR, Srinivasan R, Williams JR, Haney EB, Neitsch SL. 2011. Soil and WaterAssessment Tool : Input/Output File Documentation Version 2009. Texas: Agricultural Research Service and Texas AgriLife Research.

[2] Arsyad, S. 2000. Konservasi Tanah dan Air, Serial Pustaka, IPB Press, Bagian Proyek Penelitian Sumberdaya Agroklimat dan Hidrologi (BP2SAH) dan Bagian Proyek Pembinaan Perencanaan Sumber Air Ciliwung Cisadane, 2004. Laporan Akhir Pengembangan Teknologi Dam Parit untuk Penanggulangan Banjir dan Kekeringan. Bogor: Balai Agroklimat dan Hidrologi Bogor.

[3] Asdak, Chay. 2010. Hidrologi dan Pengelolaan Daerah Aliran Sungai. Yogyakarta: Gadjah Mada University Press.

[4] BR, Sri Harto. 1993. Analisa Hidrologi. Jakarta: Gramedia Pustaka Utama. Emiyati.2012. Hydrologic Response Unit (HRU) dan Debit Aliran Ci Rasea. Tesis.Depok: Universitas Indonesia.

[5] Firdaus, Gunadi. 2014. Analisis Respon Hidrologi Terhadap Penerapan Teknik Konservasi Tanah di Sub DAS Lengkong Menggunakan Model SWAT. Tesis.Bogor: Institut Pertanian Bogor.

[6] Gassman PW, Reyes M, Green CH, Arnold JG. 2007. The Soil and Water AssessmentTool:Historical evelopment, Applications, And Future Research Directions.America: Journal of American Society Of Agricultural And Biological Engineers ISSN 0001-2351.

[7] Hadisusanto, Nugroho. 2010. Aplikasi Hidrologi. Malang: Jogja Mediautama.
[8] Irsyad, Fadli. 2011. Analisis Debit Sungai Cidanau dengan Aplikasi SWAT. Tesis.Bogor:Institut Pertanian Bogor.

[9] Lapan. 2018. Teknologi Satelit. https://www.lapan.go.id/index.php/subb $\log / \mathrm{read} / 2018 / 5261 /$ Teknologi-Satelit/ 1973. (16 Oktober 2018)

[10] Mubarok, Z., 2014. Kajian Respons Penggunaan Lahan Terhadap Karakteristik Hidrologi DAS Way Betung. Tesis. Sekolah Pascasarjana, Institut Pertanian Bogor, Bogor

[11] Neitsch, S.L, J.G. Arnold, J.R. Kiniry, J.R. Williams. 2005. Soil and Water Assessment Tool Theoretical Documentation Version 2005. Texas: Agricultural Research

[12] Service and Texas Agricultural Experiment Station.

[13] Rau, Ibrahim Maulana. 2012. Analisis Debit Sungai dengan Menggunakan Model SWAT Pada DAS Cipasauran, Banten. Skripsi. Bogor: Institut Pertanian Bogor.

[14] Soewarno, $1995 . \quad$ Hidrologi Pengukuran dan Pengelolaan Data Aliran Sungai (Hidrometrik). Bandung: Nova.

[15] Soewarno. 2000. Hidrologi Operasional Jilid Kesatu. Bandung: PT. Citra Aditya Bakti.

[16] Suripin . 2003. Sistim Drainase Perkotaan yang Berkelanjutan,Semarang.

[17] https://hargapangan.id/tabel-harga/ pasar-modern/daerah

[18] Jogianto. (2003). Teori Portofolio dan Analisis Investasi Edisi ke-tiga. Yogyakarta: BPFE. 
[19] Rizki, Setyo Wira., Bujang Rusli, dan Evy Sulistianingsih. (2018). Analisis Portofolio Optimal Pada Index Saham LQ 45 dengan Multi-Index Models. Journal Buletin Ilmiah Mat. Stat. dan Terapannya (Bimaster) Volume 07, No. 2 (2018), hal 135 - 140.
[20] Suharsono, Sri Dewi. (2015). Perbandingan Metode Mean Variance Efficient Portofolio (MVEP) dan Model Indeks Tunggal Pada Saham Jakarta Islamic Index (JII). Yogyakarta: UIN Sunan Kalijaga. 